Research Paper:

\title{
Burnout in the Primary Caregivers of Children With Chronic Conditions and its Related Factors
}

\author{
Bahareh Ahmadi $^{1}$ (D), Mahdieh Sabery ${ }^{2}$ (D), Mohsen Adib-Hajbaghery ${ }^{2 *}$ (D) \\ 1. Department of Nursing, Imam Hossein Children's Hospital, Isfahan University of Medical Sciences, Isfahan, Iran. \\ 2. Trauma Nursing Research Center, Faculty of Nursing and Midwifery, Kashan University of Medical Sciences, Kashan, Iran
}

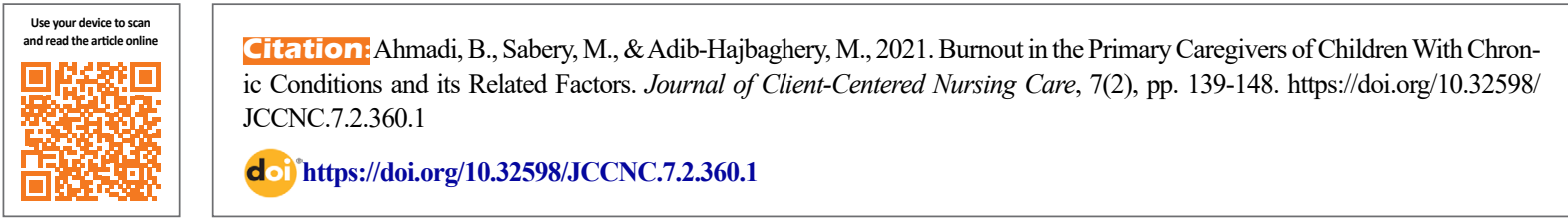

(c) (i) (9)

Article info:

Received: 19 Jan 2021

Accepted: 12 Apr 2021

Published: 01 May 2021
Keywords:

Burnout, Family caregivers, Children, Chronic illness

\section{A B S T RA C T}

Background: A majority of parents of children with chronic illness encounter physical conditions, as well as some degrees of burnout, anxiety, and depression. This study examined the prevalence of burnout in the primary caregivers of children with chronic conditions and its related factors.

Methods: A descriptive cross-sectional study was conducted on 385 family caregivers of children with chronic conditions who were selected by convenience sampling method from 4 healthcare centers in Kashan and Isfahan Provinces, Iran. A demographics questionnaire and the Maslach Burnout Inventory (MBI) were used to gather the required data. The MBI assesses caregiver burnout in 3 domains of emotional exhaustion, depersonalization, and reduced personal accomplishment. The obtained data were analyzed in SPSS using Mann-Whitney U test, Kruskal-Wallis test, Chi-Squared test, Fisher's Exact test, Analysis of Variance (ANOVA), and linear regression analysis. $\mathrm{P}<0.05$ was considered significant.

Results: The Mean \pm SD age of the examined caregivers and children were $38.2 \pm 8.04$ and $8.9 \pm 4.9$ years, respectively. Fifty percent of the research participants were fathers, and $74.3 \%$ had a family size of $>4$ members. The ill children were mostly boys (60\%) and afflicted with renal $(45.2 \%)$ or neurological $(18.2 \%)$ disorders. The mean scores of the caregivers in the 3 subscales of emotional exhaustion, depersonalization, and personal accomplishment, were 22.21, 6.40, and 13.24 , respectively. However, $62.3 \%$ and $47.9 \%$ of the caregivers experienced high or moderate levels of emotional exhaustion and depersonalization; nearly all of them (99.2\%) experienced reduced personal accomplishment. The age of the child, the type of chronic condition, the frequency of medical visits, as well as the caregiver's age, job, income, and family size, could predict caregiver burnout $\left(\mathrm{r}^{2}=0.17\right)$.

Conclusion: The family caregivers of children with chronic conditions experience moderate burnout. Nurses and other healthcare providers should be aware of the signs of caregiver burnout and its contributing factors; accordingly; appropriate plans should be made for the periodic evaluation of family caregivers.

\section{"Corresponding Author:}




\section{Highlights}

- The family caregivers of the children with chronic conditions encountered moderate burnout.

- The caregivers with lower education experienced the highest emotional exhaustion.

- Having more than two children with chronic illness was among the factors that significantly affected the mean scores of caregivers' burnout.

- Insufficient income seemed to be among the main causes of burnout in the parents and family caregivers of children with chronic conditions.

\section{Plain Language Summary}

Taking care of children with chronic diseases, managing their general and special caring needs as well as their educational and insurance organizations matters, prone parents and family caregivers to stress and burnout, and jeopardize their physical and emotional health. The present study results suggested that the majority of examined caregivers experienced high or moderate levels of burnout. The highest emotional exhaustion was experienced by the caregivers of children with disabilities, children with metabolic and immune disorders, and those with chronic neurological disorders. Caregivers with lower education experienced the highest emotional exhaustion. Also, insufficient income, having more than two children, and having more than two children with chronic illness were among the factors that significantly affected the caregivers' burnout.

\section{Introduction}

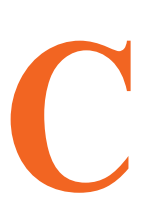

hronic diseases are the major cause of death worldwide (Buttorff, Ruder \& Bauman 2007). About $20 \%$ to $30 \%$ of children and adults in the United States suffer from chronic conditions (Brown et al. 2008). This rate is estimated to be $20.7 \%$ in Iran (Lankarani et al. 2011). Raising a child with a chronic condition or physical disability is not only challenging for the child but also for their parents and family. With the advancements in medicine and the increased life expectancy of children with chronic disorders, a major part of the required care has been transferred to their parents to be provided at home (Khanna et al. 2015; Kuhlthau et al. 2007; Lim \& Zebrack 2004). Taking care of these children, managing their general and special caring needs, as well as their educational and insurance organizations necessities, prone parents and family caregivers to stress and burnout; subsequently, such conditions impair their physical and emotional health (Ekim \& Ocakci 2016; Thompson 2009). The children's need for frequent medical visits, frequent and long-term hospitalizations, and painful diagnostic and therapeutic interventions create a stressful life, for the children and their parents (Ashkani, Dehbozorgi \& Tahamtan 2004; Ekim \& Ocakci 2016).
A study reported that family relationships were impaired in $69 \%$ of families having a child with a chronic illness, $67 \%$ of families reported sleep disorders, and $37 \%$ presented disruptive social relationships (Navidian \& Bahari 2008). Studies also suggested that a majority of parents of children with chronic illness experience physical disorders as well as some degrees of anxiety and depression (Ashkani, Dehbozorgi \& Tahamtan 2004; Hussein \& Authman 2013; Macedo et al. 2015).

Several studies examined the burden of care and burnout in the family caregivers of adult patients (Abbasi et al. 2012; Malakouti et al. 2003).

Burnout is defined as a psychosocial syndrome (Ekim \& Ocakci 2016), i.e., manifested by emotional fatigue, indifference to others, and perceived personal insufficiency or the lack of personal accomplishment (Thompson 2009). Burnout results from increased workload and role demands, and reduced ability to fulfill them. It is the consequence of long-term exposure to massive stress (Guimarães et al. 2015), that diminishes biopsychological resistance to them (Hockenberry \& Wilson 2018). Several studies focused on the perceived burden (Navidian \& Bahari 2008; Valizadeh et al. 2017), a different aspect of biopsychological health (Golics et al. 2013; Navidian \& Bahari 2008; Perricone et al. 2013; Spur- 
lock 2005; Tong et al. 2010; Valizadeh et al. 2017), and quality of life (Pruthi \& Mohta 2010) among the parents and family caregivers of children with intellectual disability (Navidian \& Bahari 2008), cancer (Valizadeh et al. 2017), and some other chronic conditions (Navidian \& Bahari 2008; Perricone et al. 2013; Valizadeh et al. 2017). These studies signified that factors, such as the type and severity of children's disease, independence level (Macedo et al. 2015), and the parents' culture, social relations (Brown et al. 2008; Macedo et al. 2015; Thompson, 2009), supportive resources, income, occupation, roles, and the number of children (Brown et al. 2008; Thompson, 2009), can contribute to the type and quality of parental experience of caring for a child with a chronic disease. However, few studies are available on burnout in the parents and family caregivers of children with chronic disorders. One of these studies has reported that $36 \%$ of the Swedish parents who had children with type 1 diabetes or inflammatory bowel disorders experienced burnout (Lindström et al. 2010). Another study in France, although overlooked reporting the prevalence of parental burnout, highlighted that parental burnout may increase the rate of sleep problems and durg use disorders among parents. Burnout in these parents was also associated with conflicts and estrangement mindset, avoidance, and suicidal ideation among the couples. Besides, it also increased the odds of negligence and violent behaviors towards their children (Mikolajczak et al. 2018). Studies on burnout in the parents and family caregivers of children with chronic conditions and its related factors are scarce. Specifically, there exists no such study in Iran. Thus, the present study aimed to examine the prevalence of burnout in the primary caregivers of children with chronic conditions and its related factors.

\section{Materials and Methods}

The present descriptive and cross-sectional study was conducted on the main family caregivers of children with chronic conditions. The study was conducted from June 2017 to September 2017. The study subjects were recruited from 4 centers, including Shahid Beheshti Hospital and the children's rehabilitation center in Kashan City, Iran, and Emam Hossein children's Hospital and Hazrate Abolfazl charity institution in Isfahan City, Iran.

The inclusion criteria of the study were having at least a child aged 1-18 years with a chronic disease that has lasted $>3$ months; being a family member who cares for and lives with the child; not having a severe psychosocial condition, and willingness to participate in the study. The caregivers were excluded if providing incomplete questionnaires.
The necessary sample size was determined based on a previous study in which the Mean \pm SD score of caregiver burnout was measured as $3.23 \pm 1.14$ (Lindström, Aman Norberg 2010). Then, considering a $\sigma$ of 0.05, a d of 0.0.1 (i.e., 0.1 of the given SD), the required sample size was estimated as 385 subjects (Formula 1).

$$
\text { 1. } n=\frac{(z)^{2}(s)^{2}}{d^{2}} \quad n=\frac{(1.96)^{2} *(6.46)^{2}}{(0.1 * 6.46)^{2}}
$$

To select the study samples, lists were prepared of all children per the inclusion criteria who had registered at the study settings. Then, using the convenience sampling method, the family caregivers meeting the inclusion criteria were invited to participate in this study. The sampling continued until the sample size was completed.

A two-part questionnaire was used in this study. The first part contained questions on demographics of the caregiver and the child, such as the age of the child and the caregiver; the type and duration of child's disease; the educational level of the child and caregiver; the caregiver's job, marital, and economic status; support resources; the size of the family; the presence of another child with a chronic condition in the family; the frequency of hospitalizations of the child in the past 6 months, and the frequency of medical visits.

The second part of the tool was the Maslach Burnout Inventory (MBI), i.e., adapted to the parents of patients with severe illnesses by Ybema et al. (Ybema et al. 2002). The MBI is a 22-item inventory in 3 domains of Emotional Exhaustion (EE) (9 items), Depersonalization (DP) (5 items), and reduced Personal Accomplishment (PA) (8 items). All the items in the EE and DP are scored on a seven-point continuum, including 'never $=0$ ', 'a few times a year or less $=1$ ', 'once a month or less $=2$ ', ' a few times a month $=3$ ', 'once a week $=4$ ', ' a few times a week $=5$ ' to 'every day $=6$ '. Items in the PA subscale are scored reversely. The possible range of scores on $\mathrm{EE}$, DP, and reduced PA are 0-54, 0-30, and 0-48 respectively. The 3 domains are independent of each other and no total burnout score is generated. Burnout is defined as the presence of high scores in both EE and DP subscales and low scores in the PA subscale. In the EE subscale, scores $0-16,17-26$, and $\geq 27$, are considered low, moderate, and high EE, respectively. In the DP subscale, scores $0-6,7-12$, and $\geq 13$ indicate low, moderate, and high DP, respectively. However, in the PA subscale, scores $\geq 39$, 22-38, and $\leq 21$ are considered low, moderate, and high reduction of PA, respectively. This inventory was translated into Persian and its validity and reliability were confirmed. The scale's Cronbach's alpha coefficient 
ranged from 0.77 to 0.88 for different subscales (Sharifi \& Fatehizade 2012).

When a caregiver agreed to participate, an appointment was arranged to visit them in a private room at a hospital, charity institution, or at their home door, where the study questionnaire was provided to them. Furthermore, they were explained how to complete it. The study subjects were requested to complete the questionnaire in a private and comfortable environment. Most of them provided completed questionnaires in $30 \mathrm{~min}$. If the study subjects could not read any part of the questionnaire, the researcher read them the questions and recorded their answers.

The obtained data were analyzed in SPSS 16. First, the Kolmogorov-Smirnov test was used to assess the normal distribution of the quantitative data. The collected data were described by mean, standard deviation, and frequency distribution. The Mann-Whitney U and KruskalWallis tests were used for between-group comparisons of the non-normal data. Categorical data were compared using the Chi-squared test and Fisher's Exact tests. Oneway Analysis of Variance (ANOVA) was used to compare normally distributed quantitative data between $\geq 3$ subgroups of the study subjects. Linear regression analysis was used to examine the predictive factors of caregiver burnout. $\mathrm{P}<0.05$ was considered significant.

\section{Results}

The Mean \pm SD age of the caregivers and children were $38.2 \pm 8.04$ and $8.9 \pm 4.9$ years, respectively. Other demographic information is presented in Tables 1 and 2 .

The mean scores of the caregivers in the 3 subscales of EE, DP, and PA were 22.21, 6.40, and 13.24, respectively. While $62.3 \%$ and $47.9 \%$ of the caregivers experienced a high or moderate level of EE and DP, nearly all of them (99.2\%) experienced reduced PA (Table 3).

Table 4 indicates that the caregivers of children with disabilities encountered the highest EE and DP; while the least PA was experienced by the caregivers of children with cardiac and respiratory diseases.

Moreover, caregivers with insufficient income, those having more children with chronic conditions, and those whose children required further medical visits obtained significantly higher scores in the EE and DP subscales and lower scores in the PA subscale, compared to their counterparts. In other words, these caregivers experienced a higher burden in all 3 subscales $(\mathrm{P}<0.05)$. How- ever, the age, marital status, and occupational status of the caregiver, as well as the child's age, number of diseases, and illness duration were not significantly related to the caregivers' EE, DP, and PA mean scores.

Furthermore, linear regression analysis data indicated that among all factors which entered the model, the child's age, chronic condition type, and the frequency of medical visits, as well as the caregiver's age, occupational status, income, and family size could significantly predict $17 \%$ of the variance in the caregiver's burnout $\left(\mathrm{r}^{2}=0.17\right)$. Among those, the major factors were income and the frequency of medical visits (Table 5).

\section{Discussion}

Approximately two-thirds of the subjects experienced moderate to severe EE, half of them experienced DP, and nearly all of them encountered reduced PA. Few studies are available on burnout in the parents or family caregivers of children with chronic conditions. Jaramillo, Moreno and Rodríguez (2016) reported that $52 \%$ of the caregivers of children with trisomy 21 suffered from EE (Jaramillo, Moreno \& Rodríguez (2016). Varghese and Venkatesan (2013) also studied the mothers of children with autism; they concluded that $85 \%$ of them presented signs of biopsychological burnout (Varghese \& Venkatesan 2013). In another study, the signs of burnout were revealed in $36 \%$ of the parents of children with chronic conditions (Sharifi \& Fatehizade 2012). Differences in the severity and frequency of burnout in family caregivers can be attributed to the type of disease and the characteristics of patients and caregivers in different studies (Varghese \& Venkatesan 2013). However, the diagnosis of a life-threatening or chronic illness in a child and its long-term treatment usually affect the parents and family. Such impacts are so severe that even after years, the parents of some of these children manifest signs of post-traumatic stress disorder (Mikolajczak et al. 2018). The enduring pressure from caregiving and parenting can lead to biopsychological and emotional problems in family caregivers; disrupt their social and familial interactions; diminish their ability to meet the needs of the ill child; hinder them to play their individual and social roles, and eventually inspire them a sense of incompetence in fulfilling such roles.

In the current study, the highest EE mean scores were respectively possessed by the caregivers of children with disabilities, children with metabolic and immune disorders, and those with chronic neurological diseases. The highest mean values of DP scores were also obtained by the caregivers of children with disabilities and chronic neurological 
Table 1. Characteristics of caregivers of children with chronic conditions

\begin{tabular}{|c|c|c|}
\hline \multicolumn{2}{|c|}{ Characteristics of Caregivers } & \multirow{2}{*}{$\begin{array}{c}\text { No. (\%) } \\
68(17.7)\end{array}$} \\
\hline & $<30$ & \\
\hline \multirow[t]{3}{*}{ Age } & $30-40$ & $194(50.4)$ \\
\hline & $>40$ & $123(31.9)$ \\
\hline & Low literate & $173(44.9)$ \\
\hline \multirow[t]{3}{*}{ Education level } & Diploma & 165 (42.9) \\
\hline & Academic & $47(12.2)$ \\
\hline & Mother & $183(47.5)$ \\
\hline \multirow[t]{3}{*}{ Kinship with the child } & Father & $193(50.2)$ \\
\hline & Others & $9(2.3)$ \\
\hline & Single & $10(2.6)$ \\
\hline \multirow[t]{5}{*}{ Marital status } & Married & $369(95.8)$ \\
\hline & Divorced & $6(1.6)$ \\
\hline & Official jobs & $35(9.1)$ \\
\hline & Self employee & $166(43.1)$ \\
\hline & & \\
\hline & Housekeeper & $176(45.7)$ \\
\hline & Retired and unemployed & $8(2.1)$ \\
\hline \multirow{2}{*}{ Numbers of family member } & $<4$ & $98(25.5)$ \\
\hline & $>4$ & $287(74.5)$ \\
\hline \multirow[b]{2}{*}{ Income } & Sufficient & $60(15.6)$ \\
\hline & Insufficient & $325(84.4)$ \\
\hline \multirow{3}{*}{ Having another sick child } & No & $290(75.3)$ \\
\hline & 2 children & $74(19.2)$ \\
\hline & $\geq 3$ & $21(5.5)$ \\
\hline \multirow{3}{*}{ Numbers of children } & 1 & $99(25.7)$ \\
\hline & 2 & $170(44.2)$ \\
\hline & $\geq 3$ & $116(30.1)$ \\
\hline \multirow{3}{*}{ Supportive resources } & Family & $254(66)$ \\
\hline & Social & $54(14.0)$ \\
\hline & No support & $77(20.0)$ \\
\hline
\end{tabular}


Table 2. Characteristics of children with chronic conditions

\begin{tabular}{|c|c|c|}
\hline \multicolumn{2}{|c|}{ Characteristics of Children } & \multirow{2}{*}{\begin{tabular}{|c|} 
No. (\%) \\
$129(33.5)$
\end{tabular}} \\
\hline & $1-6$ & \\
\hline Age, $y$ & $6-12$ & $152(39.5)$ \\
\hline & $>12$ & $104(27.0)$ \\
\hline \multirow{3}{*}{ Education level } & Low literate & $208(54.0)$ \\
\hline & Elementary education & $106(27.5)$ \\
\hline & Secondary education or higher & $71(18.5)$ \\
\hline \multirow{2}{*}{ Sex } & Boy & $232(60.3)$ \\
\hline & Girl & 153 (39.7) \\
\hline \multirow{2}{*}{ Disease duration } & 3-12 months & 75 (19.5) \\
\hline & $\geq 12$ months & $310(80.5)$ \\
\hline \multirow{7}{*}{ Type of disease } & Cardiac and respiratory disorders & $35(9.1)$ \\
\hline & Handicaps & $27(7.0)$ \\
\hline & Renal & $174(45.2)$ \\
\hline & & \\
\hline & Neural & 70 (18.2) \\
\hline & Gastrointestinal & $14(3.6)$ \\
\hline & Endocrine, metabolic and immune disorders & 65 (16.9) \\
\hline \multirow{2}{*}{ Numbers of diseases } & 1 & $310(80.5)$ \\
\hline & 2 or more & 75 (19.5) \\
\hline \multirow{3}{*}{ Intervals of medical visits } & Weekly or every 2 weeks & $89(23.1)$ \\
\hline & Every month & $264(68.6)$ \\
\hline & Every 2 months or longer & $32(8.3)$ \\
\hline \multirow{3}{*}{$\begin{array}{c}\text { Number of hospitalizations in the last } 6 \\
\text { months }\end{array}$} & $0-1$ times & $164(42.6)$ \\
\hline & $2-3$ times & $106(27.5)$ \\
\hline & $\geq 4$ & 115 (29.9) \\
\hline
\end{tabular}

Table 3. Levels of burnout among the caregivers of children with chronic conditions

\begin{tabular}{cccccc}
\hline Domains of Burnout & Mean \pm SD & Range & \multicolumn{3}{c}{ No. (\%) } \\
\cline { 5 - 7 } & & & High & Moderate & Low \\
\hline Emotional exhaustion & $22.21 \pm 15.78$ & $0-54$ & $141(36.6)$ & $99(25.7)$ & $145(37.7)$ \\
\hline Depersonalization & $6.40 \pm 6.22$ & $0-24$ & $52(13.5)$ & $132(34.4)$ & $201(52.2)$ \\
\hline Reduced personal accomplishment & $13.24 \pm 10.24$ & $0-45$ & $296(76.9)$ & $86(22.3)$ & $3(0.8)$ \\
\hline
\end{tabular}


Table 4. Mean caregivers' burnout scores in the 3 subscales according to the type of the children's diseases

\begin{tabular}{|cccc}
\hline \multirow{2}{*}{ Type of Disease } & \multicolumn{2}{c}{ Mean \pm SD } & \\
\cline { 2 - 4 } & Reduced Personal Accomplishment & Depersonalization & Emotional Exhaustion \\
\hline Cardio-Pulmonary disorders & $11.20 \pm 10.39$ & $6.01 \pm 6.30$ & $17.54 \pm 17.95$ \\
\hline Renal & $12.56 \pm 9.16$ & $6.56 \pm 5.78$ & $21.91 \pm 13.83$ \\
\hline Neural & $11.45 \pm 10.13$ & $6.75 \pm 6.49$ & $22.09 \pm 16.88$ \\
\hline Gastrointestinal & $11.95 \pm 12.11$ & $2.96 \pm 3.65$ & $14.34 \pm 14.60$ \\
\hline Metabolic and immune disorders & $17.04 \pm 12.09$ & $5.74 \pm 6.31$ & $25.35 \pm 17.02$ \\
\hline Handicaps & $16.33 \pm 8.89$ & $8.27 \pm 6.22$ & $26.96 \pm 17.28$ \\
\hline
\end{tabular}

Client- Centered Nursing Care

diseases. However, the highest levels of reduced PA were experienced by the caregivers of children with cardio-pulmonary and neurological diseases. A study reported that the type and the severity of the child's disease can affect the intensity of the caregiver's burnout (Varghese \& Venkatesan 2013). Although the burden of care deteriorates caregivers' physical and emotional health, the level of emotional exhaustion and depersonalization seems to be interconnected. Thus, the caregivers have less time for their individual affairs; consequently, such pressures reduce their PA.

In the present study, insufficient income, having $>2$ children and having $\geq 2$ children with chronic illness were among the characteristics that significantly affected the caregivers' burnout. Additionally, caregivers whose ill children required further medical visits and hospitalizations experienced higher burnout in 2-3 dimensions. Besides, the caregivers of children with $>1$ disease demonstrated a significantly higher EE, compared to the other examined caregivers. Perhaps, having a child with multiple illnesses imposes a further psycho-economic burden on family caregivers, resulting in greater emotional exhaustion. Furthermore, inadequate income seemed to be among the main causes of burnout in the parents and family caregivers of children with chronic conditions. Moreover, required further medical visits and hospitalization, and having more children will considerably increase the time and the costs the caregivers spend on caring for the child. In such conditions, caregivers' constraints will induce their feelings of inadequacy, disappointment, and energy exhaustion; subsequently, it limits their familial and social interactions, and prevent them from actualizing their personal goals (Polatçı et al. 2014).

Table 5. The regression analysis data for determining the predictive factors of caregivers' burnout

\begin{tabular}{|c|c|c|c|c|c|}
\hline \multirow{2}{*}{ Model } & \multicolumn{2}{|c|}{ Unstandardized Coefficients } & \multirow{2}{*}{$\begin{array}{c}\text { Standardized Coefficients } \\
\text { Beta }\end{array}$} & \multirow{2}{*}{$\mathbf{t}$} & \multirow{2}{*}{$\mathbf{P}$} \\
\hline & B & SE & & & \\
\hline Constant & 8.392 & 10.741 & - & 0.781 & 0.435 \\
\hline Caregiver's age, y & 0.581 & 0.201 & 0.173 & 2.892 & 0.004 \\
\hline Occupational status & 4.679 & 1.975 & 0.129 & 2.369 & 0.018 \\
\hline Economic status & -10.665 & 3.868 & -0.147 & -2.757 & 0.006 \\
\hline Family size & 3.161 & 1.511 & 0.118 & 2.092 & 0.037 \\
\hline Disease type & 1.730 & 0.556 & 0.164 & 3.109 & 0.002 \\
\hline Child's educational level & -3.719 & 1.107 & -0.185 & -3.361 & 0.001 \\
\hline The frequency of medical visits & -7.413 & 2.052 & -0.190 & -3.612 & 0.000 \\
\hline
\end{tabular}


In the present study, caregivers with lower education experienced the highest EE. However, caregivers' educational level did not significantly affect the other burnout subscales. Moreover, caregivers whose children had lower education indicated higher levels of DP. Yildizhan et al. also reported significant connections between caregiver's educational level and perceived EE and DP (Yildizhan et al. 2019). It seems that more educated individuals usually have better social interactions better job opportunities, and income, better problem solving and stress management skills, and greater self-confidence. Moreover, ill children with further education may not only present a better understanding of the disease and its treatment but also would take a greater part in their self-care. Then, the caregivers of these children may find more opportunities for familial and social interactions; consequently, they experience less DP.

Several limitations should be noted while using the results of this study. The study participants were selected from several healthcare settings. The quality of services and the severity of conditions might have affected the caregivers' burnout, i.e., overlooked in this study. Moreover, due to the cross-sectional nature of the study, precise causal relationships cannot be examined.

\section{Conclusion}

The examined family caregivers of children with chronic conditions experienced moderate burnout. Factors, such as the child's and caregiver's education, the number of diseases in a child, the size of family and number of children, and caregiver's income affected their perceived burnout. Nurses and other healthcare providers should be aware of the signs of caregiver burnout and its contributing factors; accordingly, they should develop appropriate plans for the periodic evaluation of caregivers for burnout. Consequently, they can train them to suitably cope with caregiving problems and refer them to appropriate supportive and counseling systems if necessary.

\section{Ethical Considerations}

\section{Compliance with ethical guidelines}

This study was approved by the Ethics Committee of the Institutional Review Board and the Research Ethics Committee of Kashan University of Medical Sciences (Code: IR.KAUMS.REC.1396.34). All ethical principles are considered in this article. The participants were informed about the purpose of the research and its implementation stages and signed written informed consents before participation. They were also assured about the confidentiality of their information and were free to leave the study whenever they wished, and if desired, the research results would be available to them.

\section{Funding}

This paper was extracted from the MSc. thesis of the first author at the Department of Medical Surgical Nursing, Faculty of Nursing and Midwifery, Kashan University of Medical Sciences. The current study was financially supported by the Kashan University of Medical Sciences.

\section{Authors' contributions}

All authors equally contributed to preparing this article.

\section{Conflict of interest}

The authors declared no conflicts of interest.

\section{Acknowledgments}

The authors would like to thank the Research Deputy of Kashan University of Medical Sciences for supporting the study.

\section{References}

Abbasi, A., et al. 2012. [The relationship between caring burden and coping strategies in hemodialysis patients caregivers (Persian)]. Nursing and Midwifery Journal, 10(4), pp. 533-9. http:// unmf.umsu.ac.ir/browse.php?a_id=1012\&sid=1\&slc_lang=en

Ashkani, H., Dehbozorgi, G. R. \& Tahamtan, A., 2004. Depression among parents of children with chronic and disabling disease. Iranian Journal of Medical Sciences, 29(2), pp. 90-3. https://ijms. sums.ac.ir/article_40137.html

Brown, R. T., et al. 2008. Single parents of children with chronic illness: An understudied phenomenon. Journal of Pediatric Psychology, 33(4), pp. 408-21. [DOI:10.1093/jpepsy/jsm079] [PMID] [PMCID]

Buttorff, C., Ruder, T., \& Bauman, M., 2017. Multiple Chronic Conditions in the United States [Internet]. Cited 12 April 2021, https:/ / www.rand.org/content/dam/rand/pubs/tools/TL200/ TL221/RAND_TL221.pdf

Ekim, A. \& Ocakci, A. F., 2016. Caregiver burden in pediatric Asthma: A systematic review. Health Science Journal, 10(6), pp. 1-7. [DOI:10.21767/1791-809X.1000476]

Golics, C. J., et al. 2013. The impact of patients' chronic disease on family quality of life: An experience from 26 specialties. International Journal of General Medicine, 6, pp. 787-98. [DOI:10.2147/ IJGM.S45156] [PMID] [PMCID]

Guimarães, H., et al. 2015. Parents in the neonatal intensive care unit of "Hospital de São João"(Porto, Portugal). Journal of Pediatric and Neonatal Individualized Medicine, 4(1), p. e040120. [DOI:10.7363/040120] 
Hockenberry, M. J. \& Wilson, D., 2018. Wong's nursing care of infants and children - E-book. Philadelphia: Elsevier Health Sciences. https:/ / books.google.com/books?id=w7RqDwAAQBAJ\&dq

Hussein, K. A. \& Authman, N. R., 2013. Quality of life for caregiversof children with congenital heart disease in surgical specialty hospital-cardiac center Kurdistan Region/Iraq. Kufa Journal for Nursing Sciences, 3(2), pp. 148-61. https:/ /www.iasj.net/ iasj/article/79449

Jaramillo, S., Moreno, S. \& Rodríguez, V., 2016. Emotional burden in parents of children with trisomy 21: Descriptive study in a Colombian population. Universitas Psychologica, 15(1), pp. 29-38. [DOI:10.11144/Javeriana.upsy15-1.ebpc]

Khanna, A. K., et al. 2015. Social, psychological and financial burden on caregivers of children with chronic illness: A cross-sectional study. The Indian Journal of Pediatrics, 82(11), pp. 1006-11. [DOI:10.1007/s12098-015-1762-y] [PMID]

Kuhlthau, K., et al. 2007. Policies and programs relevant to CSHCN. In: E. J. Sobo. \& P. S. Kurtin (eds.), Optimizing Care for Young Children With Special Health Care Needs: Knowledge and Strategies for Navigating the System. Baltimore MD: Paul H. Brookes Publishing Company. https://books.google.com/ books?id=G_NEAAAACAAJ\&dq

Lankarani, N. B., et al. 2011. [Chronic diseases in a populationbased study: Iranian Health Perception Survey (IHPS) (Persian)] Payesh (Health Monitor), 10(3), pp. 391-5. https:/ / payeshjournal. ir $/$ browse.php?a_id=517\&sid=1\&slc_lang=en

Lim, J. W. \& Zebrack, B., 2004. Caring for family members with chronic physical illness: A critical review of caregiver literature. Health and Quality of Life Outcomes, 2(1), pp. 1-9. [DOI:10.1186/1477-7525-2-50] [PMID] [PMCID]

Lindström, C., Aman, J. \& Norberg, A. L., 2010. Increased prevalence of burnout symptoms in parents of chronically ill children. Acta Paediatrica, 99(3), pp. 427-32. [DOI:10.1111/j.16512227.2009.01586.x] [PMID]

Macedo, E. C., et al. 2015. Burden and quality of life of mothers of children and adolescents with chronic illnesses: An integrative review. Revista Latino-Americana de Enfermagem, 23(4), pp. 769-77. [DOI:10.1590/0104-1169.0196.2613] [PMID] [PMCID]

Malakouti, S. K., et al. 2003. [The burden of caregivers of chronic mental patients and their needs to care and therapeutic services (Persian)]. Hakim Research Journal, 6(2), pp. 1-10. https:/ / www.sid.ir/fa/journal/ViewPaper.aspx?ID=501

Mikolajczak, M., et al. 2018. Consequences of parental burnout: Its specific effect on child neglect and violence. Child Abuse $\mathcal{E}$ Neglect, 80, pp. 134-45. [DOI:10.1016/j.chiabu.2018.03.025] [PMID]

Navidian, A. \& Bahari, F., 2008. Burden experienced by family caregivers of patients with mental disorders. Pakistan Journal of Psychological Research, 23(1-2), pp. 19-28. https:/ / psycnet.apa. org/record/2009-00441-003

Perricone, G., et al. 2013. Maternal coping strategies in response to a child's chronic and oncological disease: A cross-cultural study in Italy and Portugal. Pediatric Reports, 5(2), pp. 43-7. [DOI:10.4081/pr.2013.e11] [PMID] [PMCID]

Polatçı, S., Ardıç, K. \& Türkan, G., 2014. [An analysis about the effects of commitment dimensions on the burnout dimensions (Turkish)]. Yönetim ve Ekonomi Araştırmalar Dergisi, 21(2), pp. 281-92. [DOI:10.18657/yecbu.76527]
Pruthi, G. K. \& Mohta, A., 2010. Psychosocial burden and quality of life in parents of children with anorectal malformation. Journal of Indian Association of Pediatric Surgeons, 15(1), pp. 15-8. [DOI:10.4103/0971-9261.69135] [PMID] [PMCID]

Sharifi, M., \& Fatehizade, M., 2012. [Correlation between religious coping with deppression and caregiver burnout in family caregivers. (Persian)]. Modern Care Journal, 9(4), pp. 327-35. http://sid.bums.ac.ir/dspace/handle/bums/4994

Spurlock, W. R., 2005. Spiritual well-being and caregiver burden in Alzheimer's caregivers. Geriatric Nursing, 26(3), pp. 154-61. [DOI:10.1016/j.gerinurse.2005.03.006] [PMID]

Thompson, J., 2009. How chronic illness affects family relationship and the individual [PhD dissertation]. Wisconsin, University of Wisconsin-Stout. http://www2.uwstout.edu/content/lib/thesis/2009/2009thompsonj.pdf

Tong, A., et al. 2010. Parental perspectives on caring for a child with chronic kidney disease: An in-depth interview study. Child: Care, Health and Development, 36(4), pp. 549-57. [DOI:10.1111/j.1365-2214.2010.01067.x] [PMID]

Valizadeh, L., et al. 2017. Investigation on the burden of care of the mothers of children with cancer in Tabriz pediatrics treatment and educational center in 2013. International Journal of Review in Life Sciences, 7(3), pp. 71-4. https:/ / www.scienztech org/index.php/ijrls/article/view/1042

Varghese, R. T. \& Venkatesan, S., 2013. A comparative study of maternal burnout in autism and hearing impairment. International Journal of Psychology and Psychiatry, 1(2), pp. 101-8. [DOI: 10.5958/j.2320-6233.1.2.016]

Ybema, J. F., et al. 2002. Caregiver burnout among intimate partners of patients with a severe illness: An equity perspective. Personal Relationships, 9(1), pp. 73-88. [DOI:10.1111/14756811.00005]

Yildızhan, E., et al. 2019. The burden of care and burnout in individuals caring for patients with Alzheimer's disease. Community Mental Health Journal, 55(2), pp. 304-10. [DOI:10.1007/ s10597-018-0276-2] [PMID] 
This Page Intentionally Left Blank 